\title{
Infant Feeding and Conflict of Interest: A Healthcare Perspective
}

\author{
Stewart Forsyth \\ School of Medicine, University of Dundee, Retired Medical Director and Consultant Paediatrician, Dundee, UK
}

During the career of a healthcare professional, there will be many life-changing advances in pediatric clinical care and most of the developments will be the product of highly effective collaborations between researchers, clinicians, and industry. Improvements in nutritional care have increased survival of children with many chronic illnesses including neonatal, metabolic, genetic, gastrointestinal, and neurological conditions [1]. However, in the critically important area of infant and young child nutrition within the general population, partnership working, especially between the World Health Organization (WHO), and the infant food industry, has a history of acrimony and division, and consequently infant feeding issues relating to policy and practice that were prominent 5 decades ago are still relevant today [2].

The International Code of Breast Milk Substitutes (the Code) specifically affirms the need for governments, organizations of the United Nations system, nongovernmental organizations, experts in various related disciplines, consumer groups, and industry to cooperate in activities aimed at the improvement of maternal, infant, and young child health [3]. However, divisions continue and more recently officials within the WHO have turned their attention to the pediatric profession and made claims that specific aspects of their relationship with industry are a conflict of interest $[4,5]$.

A conflict of interest within a healthcare environment has been defined as a set of circumstances by which a reasonable person would consider that an individual's abil-

\section{KARGER}

๑) 2019 S. Karger AG, Basel

E-Mail karger@karger.com

www.karger.com/anm ity to apply judgment or act, in the context of delivering health care services is, or could be, impaired or influenced by another interest they hold [6]. To be more precise, an actual conflict of interest is defined as a material conflict between one or more interests, and a potential conflict is the possibility of a material conflict between one or more interests in the future. The interests are not restricted to financial benefits but also include professional, personal, and other indirect interests [6]. The recent claims of potential conflicts of interest between pediatricians and the infant food industry relate to collaborative research and sponsorship of education meetings $[4,7,8]$.

\section{Collaborative Infant Feeding Research}

In a recent Editorial in the British Medical Journal, it was stated that pediatricians should disentangle themselves from "Big Formula" $[7,8]$. However, it is important to establish that nutrition intervention studies to determine optimum nutrient requirements in infants and young children cannot be undertaken without collaborating with nutrition companies as the intervention product needs to meet established nutrition and safety standards and this requires knowledge, expertise, and technology that is not available in even the most prestigious academic research institutions [9]. The days of scientists brewing up a concoction in their laboratory and administering it to research participants are long gone. It 
is also important in these collaborative intervention studies that industry is not considered a silent partner, and their involvement should be as a full member of the research team to ensure that their compliance with scientific, ethical, funding, and research monitoring standards are fully transparent. Moreover, all in-house research by industry should also be registered with an independent research trials registry to make certain that there is no suppression of negative results. These standards should provide assurance that on submission to a journal, the information regarding all of the contributors is complete and the external reviewers and the editorial team can then make an informed decision on whether to publish or not [9].

If this process has been followed, and the article is accepted for publication, subsequent undermining of the research specifically on the grounds that it involved collaboration with industry should be challenged as professional discrimination [9]. Although many pediatricians involved in infant nutrition research have tolerated this prejudice, young researchers and clinicians today are increasingly viewing this field of research as a "no-go" area, and this undoubtedly will have a negative impact on future healthcare for children.

There needs to be a collective understanding of the potential benefits of complementary research interests across the academic and industry environments, and researchers and clinicians, who are already highly regulated professionals, should be protected and supported in both settings. With a full declaration of interest, they should be encouraged to publish and disseminate their findings at scientific and educational meetings, focusing on the science and refraining from the promotion of specific commercial products.

\section{Sponsorship of Educational Meetings}

In professional and civic society there are few events that do not attract sponsorship. Organizers of events need additional funding, and sponsors are willing to provide financial support recognizing that this may provide reputational and possible commercial benefits to their organization. In the National Health Service in England, sponsorship of health-related events by external parties is valued. It is considered that if financial support enables an education and training event to take place and it benefits health staff and patients, then sponsorship can be justified [6]. Without this funding, there may be fewer opportunities for learning, development, and partner- ship working. However, it is also recognized that there is potential for conflicts of interest between the organizer and the sponsor, particularly regarding the ability to market commercial products or services, and as a result, several safeguards are recommended to prevent conflicts occurring.

The safeguards include the assessment that the event will result in clear benefit to healthcare provision; no information will be supplied to the sponsor from which they could gain a commercial advantage; the involvement of the sponsor will be clearly identified; at the organization's discretion, sponsors or their representatives may attend the event, but they cannot influence the content or the main purpose of the event; sponsorship should not equate to endorsement of a company or its products; and finally, staff attending should declare their involvement to their organization [6].

For infant formula companies to provide sponsorship, the above conditions should apply, and additional specific safeguards that should also be considered. The proposed meeting should be limited to scientific and educational matters, the sponsor company will not input to the content and planning of the meeting, and there should be equal exposure for all sponsors. With the infant formula companies having more funding power, they currently can buy greater exposure through the current practice of offering platinum, gold, and silver sponsorships. This should be discontinued and either all sponsors commit to the same funding levels or there are funding categories that reflect ability to fund, such as private sector, public sector, charity organizations, and others.

Importantly, all sponsored healthcare events should be carefully audited to ensure the above criteria are applied and the objectives for the event are met, with this information then being readily accessible. Similar standards should apply when researchers receive sponsorship for attending meetings and congresses to disseminate their research findings; it is perfectly reasonable for them to receive expenses for their travel, accommodation, and preparation time; however, care needs to be taken to avoid contractual overlap and double payments [10].

\section{Interface between Policymakers, Pediatricians, and Industry}

The 2 examples of alleged conflict of interest highlight different viewpoints on how industry is perceived by policymakers and healthcare professionals. This reflects their different roles and objectives, with policymakers 
having responsibility for the development of policy for populations that may be national or global, whereas health professionals are focused on providing care for individual children and their families. Policymakers, especially the WHO, tend to develop one-size-fits-all global infant feeding policies, which contrasts with a more grounded healthcare approach where the needs of the child are met by providing individualized clinical care. Moreover, clinical practice is not an exact science, and some maintain it is an art, with the underlying assertion being that the best clinicians are not only knowledgeable and experienced but also have reliable clinical judgment [11]. Good judgment is extremely important in managing infant feeding issues as there are many nutritional and non-nutritional confounding factors, including health status, growth and development, culture, and socio-economic circumstances, that need to be taken into consideration when developing infant feeding policy and practice. With these different approaches, it is not surprising that health practitioners may find themselves making some clinical decisions that they believe are in the best interests of the child, but may not be compatible with global policies, including the International Code. A greater understanding of these specific circumstances may reduce the levels of acrimony that are generated by claims of conflict of interest or non-compliance with the Code.

If pediatricians are to provide the best nutritional care, they need to collaborate with industry to determine optimum nutritional requirements for infants and young children; however, this professional partnership is viewed by some as a conflict of interest $[7,8]$. The editor of the British Medical Journal has made a decision not to accept clinical editorials and education articles from authors that have had relevant financial ties with industry [12]. This presumably would exclude a scientist who was involved in the development of a vaccine against Ebola virus and during this critically important development held a contract with a pharmaceutical company. In this scenario - what is the conflict of interest and how great is the risk? Is the scientist's previous employment with a pharmaceutical company a greater conflict of interest than the $\mathrm{BMJ}$ preventing their readers from reading an educationally important scientific article? Similarly, if pediatric associations accept sponsorship from a range of donors, including infant formula companies, to support an annual educational meeting for their colleagues, are the risks from this potential material conflict of interest greater than the prevention of these educational opportunities by organizations that have a longstanding anti-industry policy?
It is evident that infant feeding research, development, and practice could become caught in an expanding web of conflicts of interest, and therefore, a rational way forward needs to be considered. A risk assessment approach has been recommended by the WHO and a process is currently being tested [13]; however, the validity of the proposal will be undermined if all relevant partners are not included in the consultation process.

\section{Managing Claims of Conflict of Interest}

Even with the best partnership working, some claims of conflict of interest will inevitably emerge; however, it is important that any claims of conflict of interest are responsible and proportionate. For this to be achieved, there must be a process that can clearly determine the level of material conflict that may influence judgment on health-related matters and thus present as a real conflict of interest. This requires a careful balance of the benefits against the risks, and this process needs to demonstrate due diligence and ensure that the evaluation does not fall victim to further conflicts of interest. A blatant conflict of interest should be easily identified; however, assessment of a potential conflict of interest introduces elements of judgment and opinion rather than fact, and in those circumstances, there may be a fine divide between good judgment, self-interest, and conflict of interest. With this potential level of uncertainty, it is particularly important that conflict of interest is not used as a tool by individuals or organizations to advance self-interest and create further division and distrust.

The WHO co-ordinate a monitoring system called NetCode in partnership with UN system organizations, WHO Collaborating Centers, NGOs who are particularly active in supporting breastfeeding, and selected Member States [14]. Their key objective is to monitor compliance with the Code and to "hold manufacturers, distributors, retail outlets, the health-care system and health-care workers to account for their breaches of national laws and/or the Code", and when violations are detected they encourage governments to impose sanctions as permitted by national legislation. However, organizations who initiated this process and also participate as monitors have a long history of preventing industry involvement in all aspects of infant feeding policy and practice, and therefore they themselves have a material conflict of interest. NetCode is clearly divisive with one half of the infant feeding community monitoring the other half, and it is noted that there is not a reciprocal arrangement. No 
reference is made to parents and therefore on which side of the divide they would cast their allegiance is uncertain. Moreover, NetCode is clearly not an independent judiciary process, and it has been stated that judicial processes should be democratic and observe human rights [15]. With the concerns expressed about sponsorship, it is noted that NetCode is not publicly funded and is currently sponsored by the Bill and Melinda Gates Foundation [14].

In conclusion, the foundations of good practice are dependent upon all organizations involved in the infant feeding community being able to demonstrate acceptable standards for professionalism, governance, and regulation and these should be assessed by an independent regulatory body. Organizations who are considered by the regulatory body not to meet these standards should not participate in infant feeding policymaking. Conflict of interest needs to be monitored and addressed if proven, but there is evidence that claims of conflict of interest may be related to underlying issues of trust and respect. Systemic changes are therefore required and these include the es- tablishment of an environment where all partners collaborate to develop a mutual understanding of the principles of infant feeding policy and practice, and this will include an acknowledgment that self-interest is inevitable and needs to be managed effectively, that progress can be achieved by compromise and incremental change, and that the overall objective is to support and protect infants and their families.

\section{Disclosure Statement}

I have received research grants from government, charitable organizations, and industry; and consultancy fees and honoraria from government and industry, including companies that produce infant formula. I currently receive consultancy fees from DSM Nutritional Products, an international ingredient supplier.

\section{Funding Sources}

There is no funding related to this manuscript.

\section{References}

1 Larson-Nath C, Goday P. Malnutrition in Children With Chronic Disease. Nutr Clin Pract. 2019 Jun;34(3):349-58.

2 Forsyth JS. International code of marketing of breast-milk substitutes-three decades later time for hostilities to be replaced by effective national and international governance. Arch Dis Child. 2010 Oct;95(10): $769-70$.

3 World Health Organisation. International Code of Marketing of Breast-milk Substitutes. 1981. Available from: https://www.who.int/ nutrition/publications/code_english.pdf (accessed February 13, 2019).

4 Costello A, Branca F, Rollins N, Stahlhofer M, Grummer-Strawn L. Health professional associations and industry funding. Lancet. 2017 Feb;389(10069):597-8.

5 Grummer-Strawn LM, Holliday F, Jungo KT, Rollins N. Sponsorship of national and regional professional paediatrics associa- tions by companies that make breast-milk substitutes: evidence from a review of official websites. BMJ Open. 2019 Aug;9(8): e029035.

6 NHS England. Managing Conflicts of Interest in the NHS. Guidance for staff and organisations. 2017. Available from: https://www.england.nhs.uk/wp-content/uploads/2017/02/ guidance-managing-conflicts-of-interestnhs.pdf.

7 Godlee F. Disentangling ourselves from "Big Formula". BMJ. 2018;363:k5146.

8 van Tulleken C. Overdiagnosis and industry influence: how cow's milk protein allergy is extending the reach of infant formula manufacturers. BMJ. 2018;363:k5056.

9 Forsyth S. Formula milk studies couldn't exist without industry. BMJ. 2019 Jan; 364:1367.

10 Booth CM, Detsky AS. From the $\$ 80$ hamburger to managing conflicts of interest with the pharmaceutical industry. BMJ. 2019 May; 365:11939.

11 Panda SC. Medicine: science or art? Mens Sana Monogr. 2006 Jan;4(1):127-38.

12 Chew M, Brizzell C, Abbasi K, Godlee F. Medical journals and industry ties. BMJ. 2014 Nov;349:g7197.

13 World Health Organisation. Safeguarding against possible conflicts of interest in nutrition programmes. 2017. Available from: http://apps.who.int/gb/ebwha/pdf_files/ EB142/B142 23-en.pdf?ua=1.

14 World Health Organization, United Nations Children's Fund. NetCode toolkit. Monitoring the marketing of breast-milk substitutes: protocol for ongoing monitoring systems. Geneva: World Health Organization; 2017.

15 Human Rights Council 35: Rule of Law. 2017. Available from: https://www.gov.uk/government/news/human-rights-council-35-ruleof-law. 